\title{
Emergency Nurses Job Satisfaction Prediction Model: Personality traits, Resilience, Emotional Expression and Ambiguity Tolerance
}

\author{
Sahar Eghbali ${ }^{1} \&$ Masoomeh Najafi ${ }^{2}$ \\ ${ }^{1}$ Department of Nursing and Midwifery, Faculty of Nursing and Midwifery, Tehran University of Medical \\ Sciences, Tehran, Iran \\ ${ }^{2}$ Department of Nursing, Faculty of Medical Science, Asadabad, Iran \\ Correspondence: Masoomeh Najafi, Department of Nursing, Faculty of Medical Science, Asadabad, Iran. Tel: \\ +98-93-9321-8122. E-mail: Najafi_masoome@yahoo.com
}

Received: December 10, 2019

Accepted: January 20, 2020

Online Published: March 30, 2020

doi:10.5539/jmbr.v10n1p37

URL: https://doi.org/10.5539/jmbr.v10n1p37

\begin{abstract}
Background: Nursing is considered as one of the most stressful jobs due to the emotional nature of the patient's demands, long working hours, professionals and interpersonal conflicts.

Aim: The purpose of present research was the study of job satisfaction predictors consisted personality traits, resilience, emotional expression and ambiguity tolerance of emergency nurses in Tehran hospitals.

Methods: This is a descriptive and correlational study. The population includes all emergency nurses in all hospitals of Tehran in 2017. The sample size consisted of 300 nurses who were selected randomly. For data collection were used NEO Personality Inventory, Berkeley Emotional Expression Questionnaire (BEQ), Job Satisfaction Survey (JSS), Resilience Scale (RS) and Ambiguity Tolerance Scale (ATS).

Results: The results demonstrate that ambiguity tolerance, resilience and emotional expression respectively had respectively the highest impact on job satisfaction, but personality traits had the lowest impact on it.

Implications for Practice: Personality traits can be a predictor of the job satisfaction of emergency nurses in hospital environment.
\end{abstract}

Keywords: Ambiguity Tolerance, Emotional Expression, Job Satisfaction, Nurses, Personality Resilience, Trait

\section{Background}

Nursing is considered as one of the most stressful jobs due to the emotional nature of the patient's demands, long working hours, professionals and interpersonal conflicts. Also nursing is under the constant social pressure. In recent decades, nurses' job satisfaction has received the attention of nursing researchers (Asri et al., 2017). Financial demands, psycho- political and human pressure in the caring field and increase workload of personnel all affect the nurses' mentality and professional performance and their job satisfaction. In recent years, the job satisfaction of the nurses has been affected by new healthcare technologies, budget cuts and change in the healthcare environment, increasing the stress in nurses (Khamisa, Peltzer, Ilic, \& Oldenburg, 2017). Health systems around the world are facing with increasing challenges, growing health needs and economic constraints. Nursing shortage and the high level of nurses leave this profession is a global problem. Job dissatisfaction is one of the important factors in nurses leave this profession. Researchers report that the low level of job satisfaction of nurses is accompanied by the high rates of desire to change the job (Meeusen, Brown-Mahoney, van Dam, van Zundert, \& Knape, 2010). Job satisfaction is positive attitudes and internal emotional reactions of a person toward his/her job that is depending on both the nature of the job and the individual's expectations of what the job should offer them (Nwafor, Immanel, \& Obi-Nwosu, 2015). Job Satisfaction is an important predictor to keep the nurses in their careers (Chang, Li, Wu, \& Wang, 2010). Nurses who have a high level of job satisfaction, they will likely stay at their job (Chang, Li, Wu, \& Wang, 2010). According to the results of a study, job satisfaction of nurses is possible not by job rotation or wage increase but by strengthening friendship and co-operation in working environment (BAŞ et al., 2017).

Job satisfaction of Nurses is one of the most studied topics in occupational and organizational research. Most studies are being implemented on external predictor factors related to job satisfaction of nurses such as organizational perspectives, working conditions, nursing job characteristics, workplace relationships, work planning, rewards, promotion, responsibilities, and job security, also leadership style and Organizational policies. 
But relatively little attention has been paid to the investigation of nurses' job satisfaction in terms of individual perspective (Chang, Li, Wu, \& Wang, 2010). Study of individual characteristics of nurses such as personality traits, resilience and the method of emotional expression and tolerance of ambiguity can be used in identification of the individual situational factors involved in nursing job satisfaction.

Personality traits are features that generally are stable in individuals and distinguish them from others and effect on their behavior. The five-factor model of the personality traits with the experimental support is one of the most prestigious and prominent personality model (Ahmadi, 2012). Personality factors in the 5-factor model are as follows: Neuroticism involves a general desire to experience negative emotions, including fear, guilt, anxiety, and hatred and disorientation. Extraversion includes features like publicity, daring and decisiveness. Experiences include imagination of inner feelings, mental curiosity, diversity, and independent judgments. Openness to experience includes imagination about inner feelings, mental curiosity, novelty seeking, and independent judgments. Agreeableness includes altruism, a high tendency to help and sympathizing with others, moving toward people and accepting criticism. Conscientiousness, includes the ability to control impulses appropriate to the community demand, and delaying satisfaction of desire and observance the norms of society. (Ahmadi, 2012). Researches have indicated to the strong relationship between personality traits and job satisfaction among nurses (Judge, Heller, \& Mount, 2002). It has been observed that people working in a similar stressful working environment report different levels of job satisfaction (Judge, Heller, \& Mount, 2002). Specter 1997, quoted by Chang et al. (Judge, Heller, \& Mount, 2002), argued that job satisfaction depends not only on the nature of the job but also on the perception and subjective assessment of the individual in which the person is working. In other words, the individual's personality can directly effect on how the work environment is interpreted and evaluated. Another variable in relation to job satisfaction in nurses is resilience (Hudgins, 2016). Resilience is the ability of successful adaptability, facing unpleasant situations (Benadé, du Plessis, \& Koen, 2017). It also involves managing daily problems and making constructive changes to events, and positive adaptation in accordance to the problems that was experienced by a person (Fletcher \& Sarkar, 2013).

Although this concept was originally developed in developmental psychology by Werner (quoted by Sefay, 2009; translated by Sadeghi et al. (Sefay, 2016)), but gradually entered other areas of psychology such as social and clinical psychology. Resilience includes a set of phenomena that, despite the serious threat to adaptation or development, are matched with good outcomes and results (Masten, 2001). Researches show that nursing students who have high resilience are more powerful in difficult and stressful conditions and show better response (Pines et al., 2014; Stephens, 2013; Taylor \& Reyes, 2012). Hudgins (2016) research shows that there is a significant relationship between job satisfaction and nurses resiliency.

Another important variable related to job satisfaction in nurses can be how people respond to confusion or tolerance of ambiguity. The concept of tolerance of ambiguity has been widely discussed since 1940 by social cognitive theorists, but there is no definite agreement on the definition and how to evaluate it. Dominant thinking about tolerance of ambiguity returns to personality traits. The concept of tolerance of ambiguity has been widely studied outside the context of social cognition, including the clinical decision of nurses and their behavior (Knight, Kenny, \& Endacott, 2016). Tolerance of ambiguity refers to the systematic and continuous tendency of individuals in respond to perceived ambiguity (more or less intensity) (McLain, Kefallonitis, \& Armani, 2015)

Emotion is another variable that is related to the level and quality of job satisfaction of nurses. Emotions at any moment affect attention, decision making, memory, physiological responses, and social interactions, even a wide range of interpersonal and intrapersonal processes are influenced by emotions (Hasani \& Bemani Yazdi, 2015). Emotion expressing is referred to as one of the main components of emotion, external emotion, regardless of value (positive or negative). Emotional expression includes behavioral changes with emotion such as facial, sound, gestures, and body movements changes (Shahgholian, Moradi, \& Kafee, 2007). People who are emotionally more powerful compare to those who do not have the ability to understand and express emotional states are more successful with negative experiences and show more suitable adaptation in relation to the environment and others (Goleman, 1995). Andonian (2013) study shows that there is a positive correlation between emotional intelligence structures (emotional expression and personality traits) and the efficiency of nurses in the internship period. The researchers did not find a report that looked at the cognitive emotional and personality dimensions as a structural model of nursing job satisfaction through careful studies of the previous research. As Chang et al. (2010) indicate that relatively little attention has been paid to assessing the job satisfaction of nurses in terms of individual and personality perspectives.

\section{Materials and Methods}

This is a descriptive and correlational research and it's a quantitative study. The population consisted of all 
nurses in the emergency department of Tehran hospitals in 2017. The sample was selected randomly from this population. The sample size was 300 nurses.

At first, a list of all public and private hospitals in Tehran was compiled. Next step, letters of request for consent to the research were sent to all hospitals in 2017. Among the hospitals, Firoozgar, Hafte Tir, Firozabad, Hazrat Rasool, Hasheminejad and Mutahari Hospitals of Tehran approved and responded and accepted the reasearch. Then, the approval questionnaires were reviewed at the Ethics Committee of hospitals. Among 500 nurses who were randomly invited to participate in the research, 350 accepted to participate in the research. After performing the research 50 questionnaires were excluded from the research process due to lack of complete response or inappropriate response, in the correction and grading phase. Finally, about 300 people's data were analyzed.

\subsection{NEO Personality Inventory}

In 1989, Costa and Mc Carey designed the short form of the five-factor Neo-personality questionnaire to measure five main factors (neuroticism, extroversion, experience, consistency, and conscientiousness) (McCrae and Costa, 1989; quoted by Muszadeh and Haji Alizadeh) (Mousazadeh \& Haji Alizadeh, 2017). This questionnaire has 60 items and it merely measures the five main factors of the personality, while its long form, in addition to the five factors, also measures its thirty dimensions. Scoring of this questionnaire on a five-point scale Likert from totally disagree to fully agreement. Correlation between short form and long form is 0.75 for conscientiousness to 0.89 for neuroticism. Validity coefficient and re-testing of the scale of this questionnaire were obtained between $75 \%$ and $83 \%$ within three months (Ahmadi, 2012). In a research, the internal consistency coefficients for each factors of neuroticism, extraversion, experience, consistency and conscientiousness were reported to be $0.86,0.73,0.56,0.86$ and 0.87 , respectively (Ahmadi, 2015). The re-test validity of this questionnaire is in a range from 0.86 to 0.90 . As well; the internal consistency of the subscales has been reported from 0.74 to 0.89 (Mousazadeh \& Haji Alizadeh, 2017).

\subsection{Berkeley Emotional Expression Questionnaire (BEQ)}

This questionnaire is a sixteen item- instrument that was developed by Gross and John (quoted from Narimani, Porsour and Basharpour) (Narimani, Porzour, \& Basharpour, 2016) and expresses the amount of emotional expression in a 7-point Likert scale of 1 (completely disagree) to 7 (I fully agreement) Measures. The impulse intensity subscale consists of 6 items and measures the severity of emotional impulses. The negative expression subscale includes 6 items that assess the intensity of the negative emotions and the positive expression subscale includes 4 items that assess the intensity of the positive emotions. The whole questionnaire shows a high internal consistency and has good test- retest reliability. Convergent and divergent validity of each subscale of this questionnaire has also been well reported (Narimani, Porzour, \& Basharpour, 2016) The scale of the Persian version of this questionnaire has shown a high correlation with the components of re- cognitive assessment and repression of the emotion regulation questionnaire (quoted by Basharpour et al. (2013)). In the study of Dobbs, Sloan and Karpinski (Dobbs, Sloan, \& Karpinski, 2007), the Cronbach's alpha coefficient of each subscale of impulsive intensity, positive and negative expressions were $0.78,0.63,0.63$ respectively and for the whole questionnaire 0.82 were obtained. Cronbach's alpha coefficient in this study was 0.79 .

\subsection{Job Satisfaction Survey (JSS)}

This survey was developed by Spector in 1985. It is used to evaluate the attitudes of employees towards their jobs. This questionnaire was translated to Persian in 2001 by Chit Chin and was used in a research (Chit Chin, 2001; quoted by Bahadori Khosroshahiet al) (Khosroshahi Bahadori, Hashemi Nosratabadi, \& Bayrami, 2013). It has 36 terms. Some of them are scored positively and others scored negatively. A positive term is a term that agreeing to it represents a job satisfaction. A nagative term is a term that agreeing to it represents job dissatisfaction (Khosroshahi Bahadori, Hashemi Nosratabadi, \& Bayrami, 2013). In a research in order to ensure the accuracy of the translation carried out by Chit-chin (Khosroshahi Bahadori, Hashemi Nosratabadi, \& Bayrami, 2013), translated Persian text into English and compared with the original questionnaire. He reported the Cronbach Alpha coefficient of 0.80 for this questionnaire. In Van Saaneet al research (van Saane, Sluiter, Verbeek, \& Frings-Dresen, 2003) with using Cronbach's alpha, the internal consistency coefficient of this test was reported 0.91 and test retest 0.71 in 18 months. And in the research of Bahadori Khosroshahi et al. (Khosroshahi Bahadori, Hashemi Nosratabadi, \& Bayrami, 2013), Cronbach's alpha was reported 0.86. Cronbach's alpha coefficient of this questionnaire was 0.83 .

\subsection{Resilience Scale}

This scale was developed by Canner and Robinson (quoted by Zautra et al.) (Zautra, Johnson, \& Davis, 2005) It is designed to test resilience (the ability to cope with stress). This scale has 25 items and the subject answers 
each item on a 5-point Likert scale (from always false (0) to completely correct (Chang, $\mathrm{Li}, \mathrm{Wu}, \&$ Wang, 2010). High scores on this scale shows high resilience. The Cronbach's alpha coefficient has been reported 0.86 (Zautra, Johnson, \& Davis, 2005). This scale was standardized in Iran by Mohammadi. To determine the validity of this scale, first the correlation of each item with the total score was calculated and then the analysis method was used. The calculation of the correlation of each score with the total score excluding 3 items showed coefficients between 0.41 and 0.44 . Then, the items of the scale were subjected to factor analysis by principal component method. The KMO value was 0.87 and the value of the chi square test in the Bartlett test was 5556.28, which showed two indicators of the adequacy of the evidence for the analysis of the factor. To determine the reliability of the Conor's self-resilience scale and Cronbach's alpha coefficient was 0.85 (Ahmadi \& Sharifi Daramadi, 2015).

\subsection{Ambiguity Tolerance Scale}

This scale created by Simons \& Gaher (Simons \& Gaher, 2005). It is a self-reporting tool that contains 15 items in which subjects are asked to degree the extent of their acceptance or opposition with the sentences on a 5-point Likert scale (Khamisa, Peltzer, Ilic, \& Oldenburg, 2017) to totally disagree (Ahmadi, 2012). The options of this scale will measure tolerance of ambiguity based on individual's ability to tolerate emotional disturbances, Mental impairment assessment, the amount of attention to negative emotions in case of occurrence and adjusting actions to relieve confusion. The disturbance tolerance with emotional disturbance $(\mathrm{r}=-0.59)$ and maladaptation $(\mathrm{r}=$ -0.51) has a negative relationship and has a significant positive relationship with positive excitement measures ( $\mathrm{r}$ $=0.26$ ). Cronbach's alpha coefficients have been reported for tolerance, evaluation, absorption and adjustment substitutions of 0.73, 0.84, 0.77 and 74 respectively (Simons \& Gaher, 2005). In the research of Shams, Azizi and Mirzaie (Shams, Azizi, \& Mirzaee, 2010), the Cronbach's alpha coefficient of this questionnaire was 0.67 and the alpha coefficient of reliability were reported by test re-test method for the whole scale was 0.81 . Cronbach's alpha coefficient in this study was 0.81 .

\section{Procedure}

After being coordinated with Roozbeh Psychiatric Hospital and gaining the satisfaction of the participants, as well as identifying men with bipolar disorder, first aim of this study was explained to them and were asked them to read the questions carefully and choose the desired responses according to their own characteristics, and answer to questions as many as possible. Data were collected on an individual basis at related centers. Finally, the collected data were analyzed using Pearson correlation and multiple regression statistical techniques. Also, the ethical issues including ensuring the participants about the confidentiality of their information and freedom of choice for participation in the study project observed in this research.

\section{Ethical Considerations}

The research objectives were fully described for subjects. The consent was obtained for participation in the research (we agreed that the personal information of the subjects should remain confidential).

\section{Results}

To describe the research data, some descriptive statistics values are presented below.

Table 1. Results of descriptive statistics (mean and standard deviation) of research variables

\begin{tabular}{lclll}
\hline & variables & Maximum & Mean & Standard Deviation \\
\hline \multirow{4}{*}{ Personality trait } & Job Satisfaction & 191 & 159.153 & 15.85 \\
& Tolerance of ambiguity & 75 & 54.156 & 5.464 \\
& Resilience & 104 & 73.21 & 14.41 \\
& Extraversion & 78 & 55.243 & 8.280 \\
& Openness to experience & 34 & 25.100 & 3.248 \\
\multirow{3}{*}{ Emotional expression } & Agreeableness & 41 & 32.456 & 4.159 \\
& Neuroticism & 47 & 34.893 & 4.784 \\
& Conscientiousness & 39 & 27.220 & 3.859 \\
& Expressive & 49 & 35.873 & 4.944 \\
\hline
\end{tabular}


Table 2. One-way variance ANOVA analysis of variables based on gender

\begin{tabular}{lclll}
\hline & Observed Variables & F & Significancy & result \\
\hline & Job Satisfaction & 2.433 & 0.120 & Meaningless difference \\
& Tolerance of ambiguity & 0.092 & 0.762 & Meaningless difference \\
& Resilience & 2.727 & 0.100 & Meaningless difference \\
\multirow{3}{*}{ Personality trait } & Extraversion & 5.754 & 0.017 & significant difference \\
& Openness to experience & 6.633 & 0.010 & significant difference \\
& Agreeableness & 11.991 & 0.001 & significant difference \\
\multirow{2}{*}{ Emotional expression } & Neuroticism & 9.105 & 0.003 & significant difference \\
& Conscientiousness & 1.585 & 0.209 & Meaningless difference \\
& Expressive & 2.709 & 0.101 & Meaningless difference \\
\hline
\end{tabular}

According to the results of the above table, the significance levels of the test for all variables are higher than the significance level (0.05). Consequently, in this dimension, the gender is estimated to be the same, and the assumption of the test based on the difference in variables is not accepted by the $95 \%$ confidence level. Except extraversion, Openness to experience, agreeableness and Conscientiousness whose significance level is less than (0.05). The result is not the same in terms of gender, and the assumption of the test based on the difference of extraversion, Openness to experience, agreeableness, and Conscientiousness by gender is accepted confidently $95 \%$.

Table 3. One-way variance analysis ANOVA Research variables based on work shift

\begin{tabular}{|c|c|c|c|c|}
\hline \multicolumn{2}{|r|}{ Observed Variables } & $\mathrm{F}$ & Significancy & result \\
\hline \multicolumn{2}{|r|}{ Job Satisfaction } & 7.504 & 0.007 & significant difference \\
\hline \multicolumn{2}{|r|}{ Tolerance of ambiguity } & 11.055 & 0.001 & Meaningless difference \\
\hline \multicolumn{2}{|r|}{ Resilience } & 1.614 & 0.205 & significant difference \\
\hline \multirow{5}{*}{ Personality trait } & Extraversion & 11.680 & 0.001 & significant difference \\
\hline & Openness to experience & 2.271 & 0.133 & Meaningless difference \\
\hline & Agreeableness & 0.215 & 0.643 & Meaningless difference \\
\hline & Neuroticism & 17.781 & 0.000 & significant difference \\
\hline & Conscientiousness & 0.435 & 0.510 & significant difference \\
\hline \multirow{2}{*}{ Emotional expression } & Expressive & 0.017 & 0.896 & Meaningless difference \\
\hline & Impulsive & 2.849 & 0.092 & Meaningless difference \\
\hline
\end{tabular}

According to the results of the above table, the significance levels of the test for all variables are higher than the significance level (0.05). Consequently, in this dimension, the work shift is estimated to be the same, and the assumption of the test based on the difference in variables is not accepted in a $95 \%$ confidence interval, except job satisfaction, tolerance of ambiguity, extraversion, Conscientiousness a significant level of less than (0.05). As a result, the work shift is not the same, and the assumption of the test based on the difference in job satisfaction, tolerance of ambiguity, extraversion, and Conscientiousness is based on a $95 \%$ confidence.

Figure 1 shows the estimated standard coefficients for the variables. Job Satisfaction was considered as dependent variable and tolerance of ambiguity, personality traits, emotional expression and resilience were considered as independent variables. Standardized coefficients show that tolerance of ambiguity, resilience and emotional expression have the highest impact and ultimately personality traits have the least impact on job satisfaction. The value of the determination coefficient for the model is below 0.76 . In other words, 76 percent of job satisfaction is expressed by personality factors. 


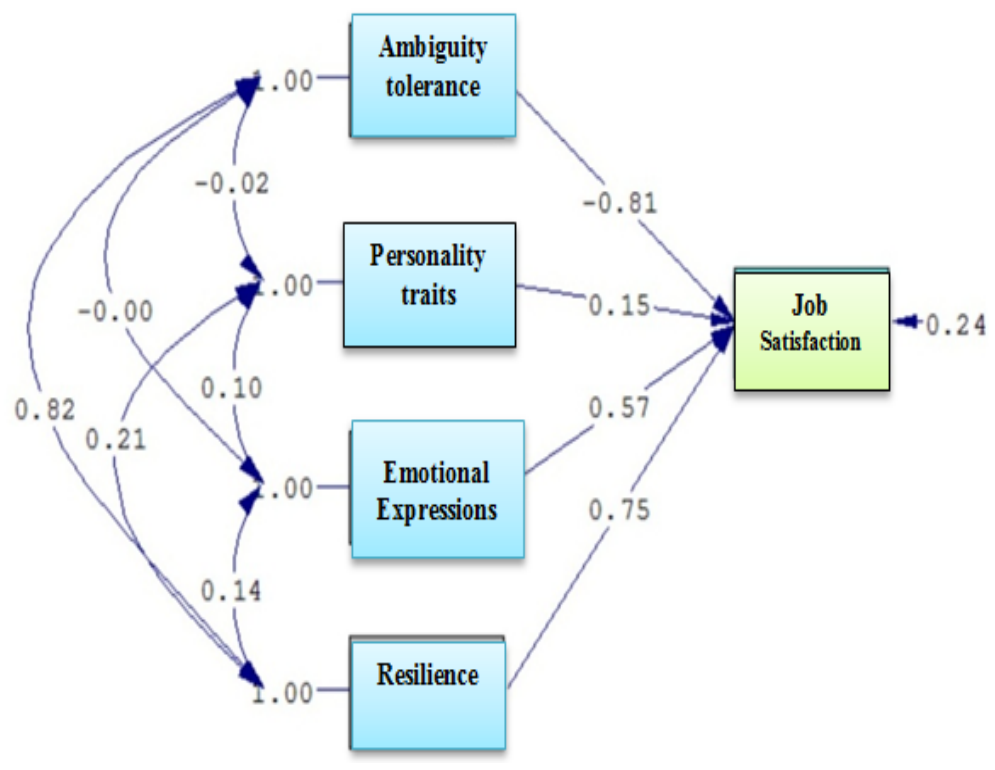

Figure 1. The model for estimating standard coefficients for variables was observed

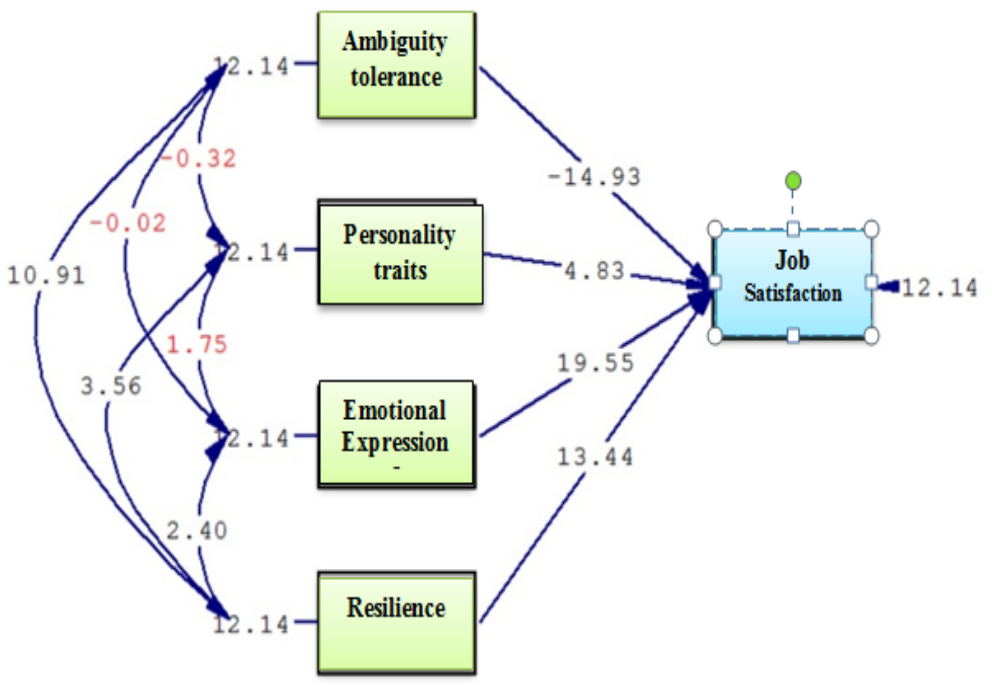

Figure 2. Test model Estimates of standard coefficients for observed variables

Also Pearson correlation coefficients between the observed variables have been tested. Regarding the significance level, linear relationship between resilience, tolerance of ambiguity, personality traits and emotional expression with job satisfaction variable was significant at $99 \%$ confidence level. The linear relationship between resilience and emotional expression, tolerance of ambiguity, emotional expression and personality traits, and emotional expression were at the $95 \%$ confidence level (meaningful less than 0.05 ).

\section{Discussion}

The purpose of this study was to study the predictors of job satisfaction among nurses in the emergency unit. The results of the standard estimation test showed that the tolerance of ambiguity, resilience and emotional expression had the highest impact and personality traits had the least impact on job satisfaction. The value of the determination coefficient for the model is below 0.76 . In other words, 76 percent of job satisfaction is expressed by the above factors. This finding is in line with previous studies such as Wittenberg and Norcross (Wittenberg \& Norcross, 2001), Hudgins (2016) and Chang et al. (2010).

Researchers have identified and studied many factors as predictors of job satisfaction among nurses, most of 
these factors emphasize on nursing work status. Because nursing is associated with physical and emotional aspects of working environments. In other words, the environment and situation in which the nurse is placed needs some of the characteristics and personality traits that predict their job satisfaction. One of the predictors of job satisfaction is the ability of the individual to respond in a systematic and sustainable way to ambiguity in the workplace. In stressful working environments such as the hospital and the emergency department, a nurse can have a good performance when $\mathrm{s} / \mathrm{he}$ is prepared to deal with and manage critical and unpredictable situations; and on the other hand, show high resilience facing with of different conditions (Benadé, du Plessis, \& Koen, 2017). Hudgins (2016) showed that there is a significant relationship between job satisfaction and resilience of nurses. Persons who are emotionally and capable and capable of expressing it will be more successful in coping with the ahead of challenges (Dobewall, Aavik, Konstabel, Schwartz, \& Realo, 2014). Individuals who are emotionally empowered recognize their feelings, understand implicit concepts, and more effectively express their emotional states to others. Therefore, emotional expressiveness can affect the individual's job satisfaction. As in the present research, it was found that there was a significant relationship between emotional expressiveness and job satisfaction among nurses. In other words, expressing emotions in time, place and position can lead to positive outcomes (Rahdari, Modarres Gharavi, \& Tabibi, 2010).

As well, in the present research model it was found that personality traits (although low impact) can effect on job satisfaction. Judge et al. in their research in 2002 pointed to the relationship between personality traits and job satisfaction among nurses. Person who have more neurotic traits than other personality traits have a lot of emotional and cognitive problems, therefore have many shortcomings and tensions in interpersonal, social and occupational environments. In other words, with the increase in neuroticism, the active interaction with the environment decreases and the individual loses some of its supporting resources (Ahmadi, 2015). Therefore, nurses with higher neurotic symptoms will probably have more negative emotions. As a result, the person's tendency to openness to experience and to get into new situations will be reduced and this creates a situation of tension due to dissatisfaction with the current situation and the lack of a change in the present situation. In other words, the existence of some negative personality traits can lead to negative emotional expressions, which can be attributed to the low level of job satisfaction in the individual. The limitations of the present study were to conduct research in the private hospitals. Because working conditions in government hospitals is different in terms of salaries and benefits, etc. This is due to the lack of cooperation of state hospitals in participating in the research process. Also, the conditions and facilities of Tehran hospitals are very different from the other cities; generalizing these events to the whole society should be considered cautiously. The lack of investigation of the subjects' mental status during the conduct of research was one of the other limitations of this study. Therefore, it is suggested that in future studies governmental hospitals be investigated, and studies should be done in other provinces and cities.

\section{Implications for Practice}

Considering the findings of this study, it seems that, the nursing profession is associated with the physical and emotional aspects of working conditions, consideration of the environment, position and personality traits of nurses in accordance with the work situation can be they are important in their job satisfaction. This can be more important, especially for the nurses working in the emergency unit in the hospitals, and experiencing more difficult and critical situations.

\section{Acknowledgements}

We sincerely thank all the nursess, Hospital principals, and administrative staff for their participation in this study.

\section{Funding}

The study was carried out without any grant from any organization.

\section{Conflict of interests}

The authors declare that there is no conflict of interests regarding the publication of this paper.

\section{References}

Ahmadi, M. (2012). The Relationship Between the five-factor Personality Traits and the Emotional Intelligence of Male and Female Miane Islamic Azad University Students. Knowledge \& Research in Applied Psychology, 13(2), 44-53.

Ahmadi, M. (2015). Predicting Job Stress and Burnout based on Personality Characteristics of Nurses. Knowledge \& Research in Applied Psychology, 17(2), 98-107. 
Ahmadi, R., \& Sharifi Daramadi, P. (2015). A Study of the Effect of Resilience Training on Mental Health of People with Drug Dependency at Touska Camp in Tehran. J Clin Psy Stud, 4(16), 1-17.

Andonian, L. (2013). Emotional intelligence, self-efficacy, and occupational therapy students' fieldwork performance. Occupational Therapy in Health Care, 27(3), 201-15.

Basharpoor, S., Molavi, P., Sheykhi, S., Khanjani, S., Rajabi, M., \& Mosavi, S. A. (2013). The Relationship between Emotion Regulation and Emotion Expression Styles with Bullying Behaviors in Adolescent Students. J Ardabil Univ Med Sci., 13(3), 264-275.

Benadé, P., du Plessis, E., \& Koen, M. P. (2017). Exploring resilience in nurses caring for older persons. Health SA Gesondheid, 22(Supplement C), 138-49.

Chang, Y. H., Li, H. H., Wu, C. M., \& Wang, P. C. (2010). The influence of personality traits on nurses' job satisfaction in Taiwan. International Nursing Review, 57(4), 478-84.

Dobbs, J. L., Sloan, D. M., \& Karpinski, A. (2007). A psychometric investigation of two self-report measures of emotional expressivity. Personality and Individual Differences, 43(4), 693-702.

Dobewall, H., Aavik, T., Konstabel, K., Schwartz, S. H., \& Realo, A. (2014). A comparison of self-other agreement in personal values versus the Big Five personality traits. Journal of Research in Personality, 50(Supplement C), 1-10.

BAŞ, T., ÜNAL, O., Amarat, M., SAĞLIK, D. (2017). THE EFFECT OF JOB SATISFACTION OF NURSES ON MOTIVATION. Journal Of Organizational Behavior Research, 2(2), 20-39.

Fletcher, D., \& Sarkar, M. (2013). Psychological resilience: A review and critique of definitions, concepts, and theory. European Psychologist, 18(1), 12-23.

Goleman, D. (Ed.) (1995). Emotional Intelligence. New York: Bantam books.

Hasani, J., \& Bemani Yazdi, B. (2015). The relationship between emotional expression styles and Type D personality. Medical Sciences, 25(2), 141-150.

Hudgins, T. A. (2016). Resilience, job satisfaction and anticipated turnover in nurse leaders. Journal of Nursing Management, 24(1), E62-9.

Judge, T. A., Heller, D., \& Mount, M. K. (2002). Five-factor model of personality and job satisfaction: A meta-analysis. The Journal of Applied Psychology, 87(3), 530-41.

Khamisa, N., Peltzer, K., Ilic, D., \& Oldenburg, B. (2017). Effect of personal and work stress on burnout, job satisfaction and general health of hospital nurses in South Africa. Health SA Gesondheid, 22(Supplement C), 252-8.

Khosroshahi Bahadori, J., Hashemi Nosratabadi, T., \& Bayrami, M. (2013). The relationship between psychological capital and personality traits with job satisfaction among librarians' in public libraries in Tabriz. Pajoohandeh, 17(6), 313-9.

Knight, K., Kenny, A., \& Endacott, R. (2016). From expert generalists to ambiguity masters: Using ambiguity tolerance theory to redefine the practice of rural nurses. Journal of Clinical Nursing, 25(11-12), 1757-65.

Masten, A. S. (2001). Ordinary magic. Resilience processes in development. The American Psychologist, 56(3), 227-38.

McLain, D. L., Kefallonitis, E., \& Armani, K. (2015). Ambiguity tolerance in organizations: Definitional clarification and perspectives on future research. Frontiers in Psychology, 6, 344.

Meeusen, V. C., Brown-Mahoney, C., van Dam, K., van Zundert, A. A., \& Knape, J. T. (2010). Personality dimensions and their relationship with job satisfaction amongst Dutch nurse anaesthetists. Journal of Nursing Management, 18(5), 573-81.

Mousazadeh, O., \& Haji Alizadeh, K. (2017). Prediction of Depression Based on Dysfunctional Attitudes, Personality Traits, and Family Communication Patterns among Patients with Epilepsy. Journal of Shefaye Khatam, 5(4), 47-56.

Narimani, M., Porzour, P., \& Basharpour, S. (2016). Comparison of negative mood setting and expressive expression in students with and without Special learning disorder. Quarterly Journal of Research in Educational Systems, 9(31), 69-90. 
Nwafor, C. E., Immanel, E. U., \& Obi-Nwosu, H. (2015). Does nurses' self-concept mediate the relationship between job satisfaction and burnout among Nigerian nurses. International Journal of Africa Nursing Sciences, 3(Supplement C), 71-5.

Pines et al. (2014). Enhancing resilience, empowerment, and conflict management among baccalaureate students: Outcomes of a pilot study. Nurse Educator, 39(2), 85-90.

Asri, V., Ali Ali Asghari Tabrizi, F. (2017). Comparing emotional intelligence, sense of self-efficacy, and jobsatisfaction among nurse educatorsa case of national university and Islamic Azad University Of Ardabi. Pharmacophore, 8(6), 34-40.

KURT, S., DEMIRBAG, B.C. (2018). Job satisfaction levels of nurses working at public hospitals. Journal of Organizational Behavior Research, 3(2), 242-253.

Rahdari, M., Modarres Gharavi, M., \& Tabibi, Z. (2010). On the relationship between personality traits and level of expressed emotion in mothers of schizophrenic patients. Journal of Fundamentals of Mental Health, 1(45), 438-47.

Sefay, K. (2016). Promoting educational resilience in the classroom. Translated by Sadeghi H, Abolghasemi A, Kiamarsi A. Behandishan Publication.

Shahgholian, M., Moradi, A., \& Kafee, M. (2007). Relationship of Alexithymia with Emotional Expression Styles and General Health among University Students. IJPCP, 13(3), 238-248.

Shams, J., Azizi, A., \& Mirzaee, A. (2010). Correlation between Distress Tolerance and Emotional Regulation With Students Smoking Dependence. Hakim, 13(1), 11-8.

Simons, J. S., \& Gaher, R. M. (2005). The Distress Tolerance Scale: Development and Validation of a Self-Report Measure. Motivation and Emotion, 29(2), 83-102.

Stephens, T. M. (2013). Nursing student resilience: A concept clarification. Nursing Forum, 48(2), 125-33.

Taylor, H., \& Reyes, H. (2012). Self-efficacy and resilience in baccalaureate nursing students. International Journal of Nursing Education Scholarship, 9, 2.

van Saane, N., Sluiter, J. K., Verbeek, J. H., \& Frings-Dresen, M. H. (2003). Reliability and validity of instruments measuring job satisfaction--a systematic review. Occupational Medicine (Oxford, England), 53(3), 191-200.

Wittenberg, K. J., \& Norcross, J. C. (2001). Practitioner perfectionism: Relationship to ambiguity tolerance and work satisfaction. Journal of Clinical Psychology, 57(12), 1543-50.

Zautra, A. J., Johnson, L. M., \& Davis, M. C. (2005). Positive Affect as a Source of Resilience for Women in Chronic Pain. Journal of Consulting and Clinical Psychology, 73(2), 212-20.

\section{Copyrights}

Copyright for this article is retained by the author(s), with first publication rights granted to the journal.

This is an open-access article distributed under the terms and conditions of the Creative Commons Attribution license (http://creativecommons.org/licenses/by/4.0/). 